\title{
Use of Lactobacillus rhamnosus GG Agaist Infection with Secondary Hydatid Disease in Swiss BABA/c Mice
}

\author{
Tasneem Younis \\ Department of Biology \\ College of Science \\ University of Kirkuk \\ Email: tasneembio93@gmail.com
}

\author{
Asmaa Abdul Aziz Ali \\ Department of Biology \\ Education College for Pure Sciences \\ University of Mosul \\ Email: assssali@uomosul.edu.iq
}

\author{
Neama Ali Ahmad \\ Department of Biology \\ College of Science \\ University of Kirkuk \\ Email: nama_1974@yahoo.com
}

DOI: $\underline{10.33899 / \text { edusj.2019.162974 }}$

$$
\begin{gathered}
\text { Received } \\
20 / 03 / 2019
\end{gathered}
$$

\author{
Accepted \\ $10 / 04 / 2019$
}

\begin{abstract}
The present study investigated the effect of probiotic bacteria lactobacillus GG $\left(13 \times 10^{5} \mathrm{CFU} / 0.1 \mathrm{ml}\right)$ on the immune response of Swiss BALB/c mice (injected intraperitoneally), against experimental Infection with protoscoleces of Echinococcus granulosus (Postinfection), in comparison with the control group (mice injected with protoscoleces only) for 2-5 months. Another experimental group of mice inoculated (orally) with L.rhamnosus GG $\left(8 \times 10^{7} \mathrm{CFU} / 0.1 \mathrm{ml}\right)$ preinfection with protoscoleces for 3 months. Depending on many criteria including numbers, weights, diameters of developed hydtid cysts, and the percentage of their reduction, the results revealed a significant decrease $(\mathrm{P} \leq 0.05)(\mathrm{P} \leq 0.01)$ in numbers, weights and diameters of hydatid cysts in treated mice, expressed by the percentage reduction elevation of their numbers to $(98 \%)$ in mice treated intraperitoneally (2-5 months) post infection, and $95 \%$ in mice treated orally 3 months pre infection, as compared with the control groups.
\end{abstract}

Key words: Probiotics, Lactobaciuus rhamnosus, Hydatid disease, Echinococcus granulosus. 


\section{استخدام بكتريا Lactobacillus rhamnosus GG ضد الاصابة بداء الأكياس العدرية}

\section{الثانوي في الفئران السويسرية BALB/c}

\author{
نعمة علي احمد \\ قسم علوم الحياة/ كلية العلوم \\ جامعة كركوك \\ nama11974@yahoo.com
}

\author{
اسماء عبد العزيز علي \\ قسم علوم الحياة/ كلية التربية \\ جامعة الموصل \\ assssali@uomsul.edu.iq
}

\author{
تسنيم يونس طركي \\ قسم علوم الحياة/ كلية العلوم \\ جامعة كركوك
}

tasneembio93@gmail.com

DOI: $\underline{10.33899 / \text { edusj.2019.162974 }}$

القبول

2019 / 04 / 10
الاستلام

2019 / 03 / 20

\section{الخلاصة}

تناولت الدراسة الحالية تأثير بكتريا في الاستجابة المناعية للفئران السويرية سلالة BALB/c (بطريقة الحقن داخل البريتوني) بعد الاصيابة بالرؤيسات الأولية لدودة المشوكة الحبيبية Echinococcus granulosus, مقارنة بمجموعة السيطرة (فئران محقونة برؤيسات اولية غير معاملة بالبكتريا) لمدة 2-5 أشهر , إضافة إلى مجموعة تجرببية أخرى من الفئران

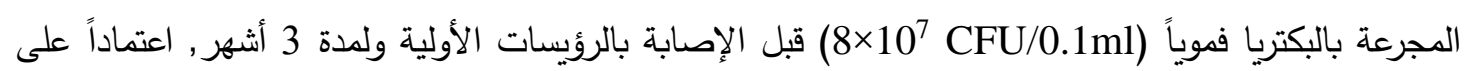

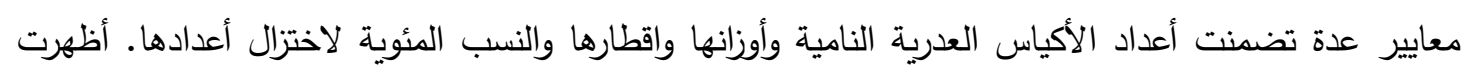

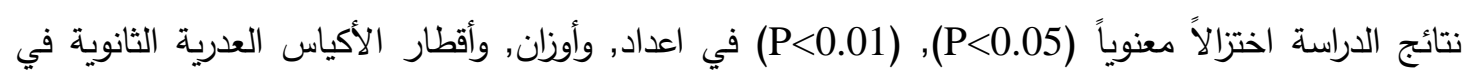

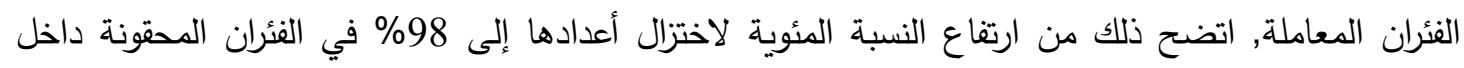
البريتون بعد 2-5 أثهر من الإصابة, و95\% في الفئران المجرعة فموياً, قبل الإصابة لمدة 3 أشهر .

الكلمات الدالة: بكتريا Pactobacillus rhamnosus، Probiotics، داء الأكياس العدرية، علاج الطفيليات, .Echinococcus granulosus

\section{Introduction المقدمة}

تعد المشوكة الحبيبية E. granulosus هي الدودة الشريطية المسببة لداء المشوكات الكيسي Cystic echinococcosis

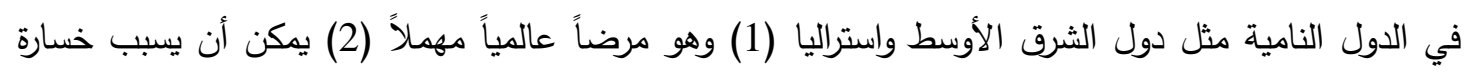

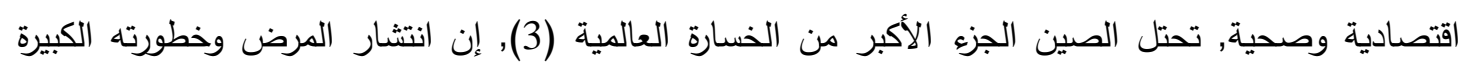

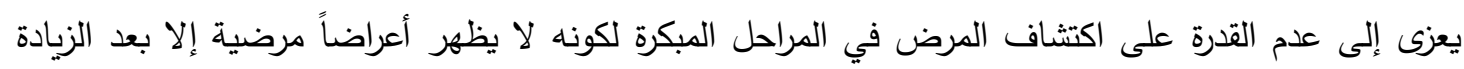

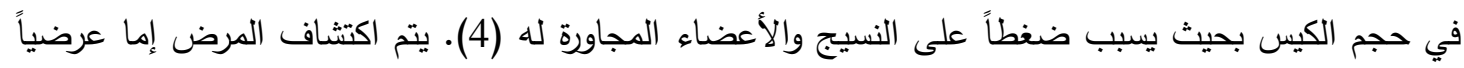

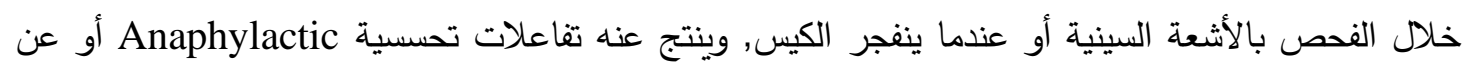
طريق التشريح ما بعد الموت (5). 
يستند تشخيص داء العدريات أيضاً على الطرق التشخيصية المناعية, وتتضمن طريقة التلازن غير المباشر Indirect haemagglutination, الومضان المناعي غير المباشر Indirect immunofluoresence, الترحيل المناعي الكهربائي Counter-current immunoelectrophoresis, اختبار الروز المناعي Radioimmunoassay, والادمصاص المناعي المرتبط بالإنزيم Enzyme-Linked Immunosorbent (ELISA) Assay (5) كما استخدم الباحثون طرائق التصوير والطرائق المصلية والجزيئية للكثف عن داء المشوكات الحبيبية (6).

توجد طرائق عديدة لعلاج داء المشوكات الكيسي ولكن حالياً هناك ثلاثة خيارات, أولها: الجراحة التي تعد المعالجة الرئيسة للمرض (7), ولكن يجب تجنب انتشار (سكب) محتويات الكيس واستخدام العوامل الفعالة القاتلة للرؤيسات الأولية Protoscolicidals لتقليل نسبة الإصابة الثانوية, يحتاج الجراحون مواداً أقل تأثيراً على النسج وأكثر فاعلية في قتل الرؤيسات الأولية الموجودة في الكيس, ولا تتأثر بالتخفيف مع سائل الأل

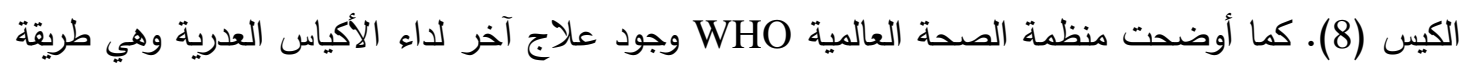
السفط والحقن Puncture Aspiration Injection Respiration (PAIR). تكون هذه الطريقة أكثر تأثيراً من الجراحة في حالة تكرار الإصابة وعودتها (9) ويشترط فيها مهارة عالية ودراية كافية تجنباً لخطر الإصابة الثانوية (10), كذلك استخدمت طرائق استئصال الكيس العدري مثل استخدام الإشعاع (11), والمايكروويف وديف

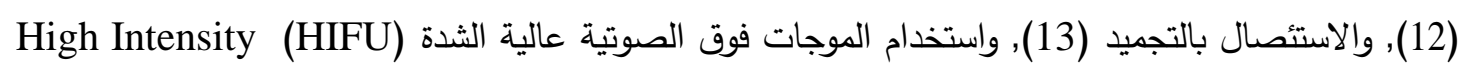
Chen et al (7) أن تأثير الذبذبات الصغيرة جداً على (14,15) Focused Ultrasound الغشاء الخلوي يكون ذا معنوية بيولوجية ولهذا ركزوا على دراستها وهدفوا إلى التحري عن التأثيرات الحيوية للتيار الكهربائي المقاس بـ nanosecond Pulsed Electric Field (nsPEF) على الكيس العدري المتعدد الأغشية للإنسان, وقد لاحظوا التأثير الاستثائي للذبذبات الدقيقة على التركيب الغشائي للكيس من ناحية النضوحية ومن الناحية الكيميائية الحياتية. يعد البندازول Albendazole الدواء المثالي للمرض, ولكن تراكيز العلاج في العضو المتأثر تكون عادة قليلة بسبب جدران الكيس السميكة, وإن زيادة الجرعة والاستخدام لفترات طويلة قد يكون لها تأثيرات جانبية مثل الإسهال Diarrhea والغثيان Nomiting والتيء لقدئ والزيادة في انزيم تعداد كريات الدم البيضاء Leucopenia (16,17). لذا, فقد اتجه الباحثون في السنوات الأخيرة إلى ايجاد بدائل أفضل وتطوير استراتيجيات بديلة, منها

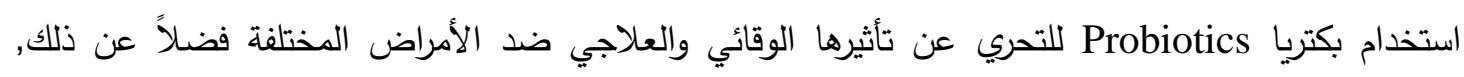

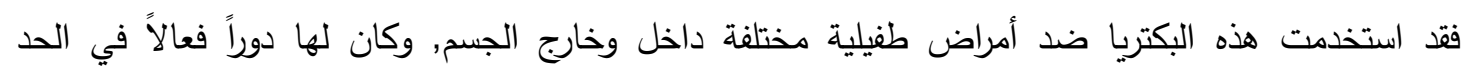

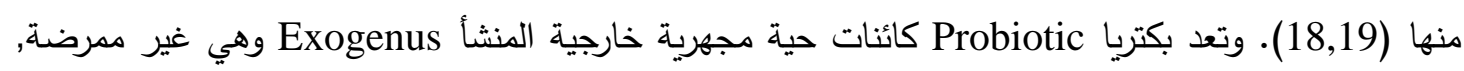
ولها القدرة على تحمل مستويات pH الحامضية وتحمل حموضة الأمعاء (20). تعود الكائنات الحية المجهرية التي تتتمي إلى بكتريا Probiotics في الإنسان بشكل رئيس الإهلى الأجناس Lactobacillus, Bifidobacterium, Lactococcus, Streptococcus, Enterococcus, بكتئ يضاف إلى ذلك سلالات البكتريا الموجبة لصبغة كرام التي تعود إلى جنس Bacillus وبعض سلالات الخمائر

التي تتتمي إلى جنس Saccharomyces وتستخدم أيضاً بصورة شائعة في منتجات Probiotics (21). تعرف الـ Probiotics بامتلاكها تأثيرات ايجابية على المضيف من خلال تحسين التوازن الطبيعي للبكتريا الموجودة في الأمعاء Microbiota وتعزيز صحة الحيوان (22), كما يمكن أن يتم تحوير الأثكال 
الميكروبية المعوية بواسطة بكتريا Probiotics وذلك لتوفير ظروف ملائمة لتعزيز النمو والصحة, وتستطيع

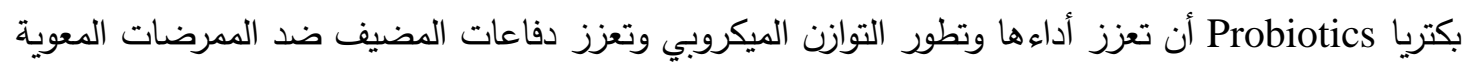

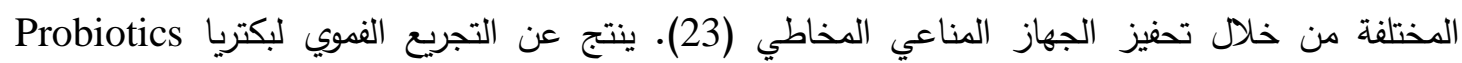

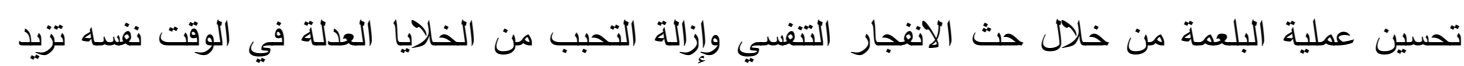
سعة البلعمة للخلايا البلعمية الكبيرة (24). تعد بكتريا L. rhamnosus GG إحدى أكثر السلالات البكتيرية التابعة لا Probiotics استعمالاً, وقد عزلت بكتريا ATCC 53103 L. rhamnosus GG (LGG) من النماذج البرازية للبالغين الأصحاء من قبل Sherwood Gorbach Barry Goldwin

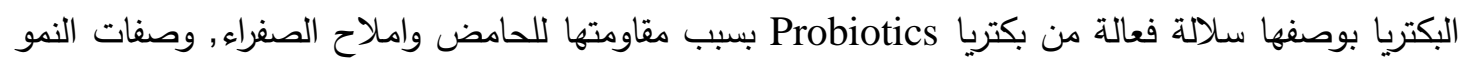

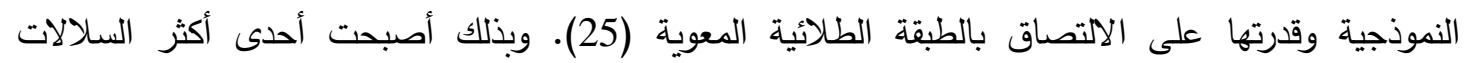

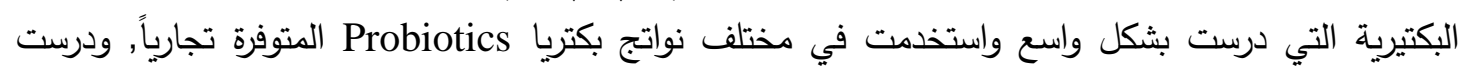
التأثيرات الايجابية لهذه البكتريا بشكل واسع في التجارب السريرية وفي الدراسات على الإنسان (26).

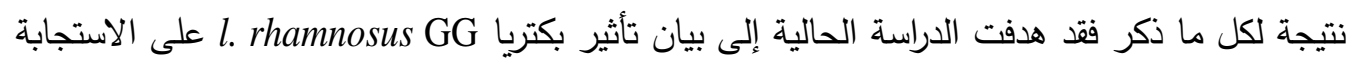
المناعية في الفئران البيض السويسرية BALB/C ضد الإصابة بداء الأكياس العدرية الثانوي داخل الجسم in vivo

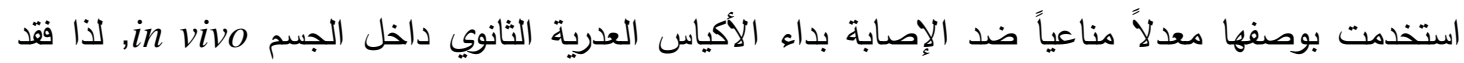

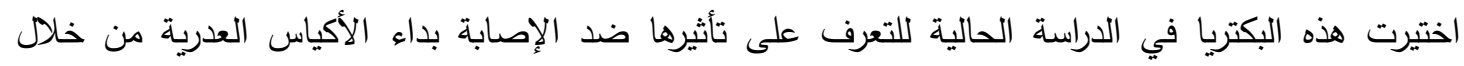

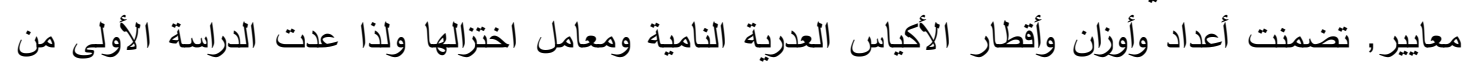
نوعها ولبنة أولية لهكا دراسات بشأن علاج الأمراض الطفان الطيلية.

المواد وطرائق العمل

عزل وفحص الأكياس العدرية Isolation and hydatid Cysts Test تم الحصول على الأكياس العدرية (الصورة 1) بعد عزلها من أكباد الأغنام المذبوحة من محلات الجزارة

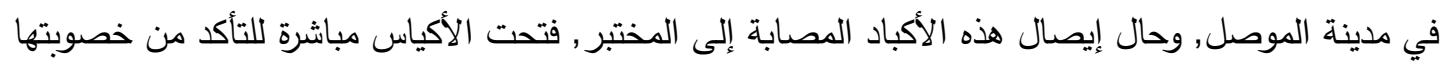
من خلال وجود الرؤيسات الأولية داخلها.

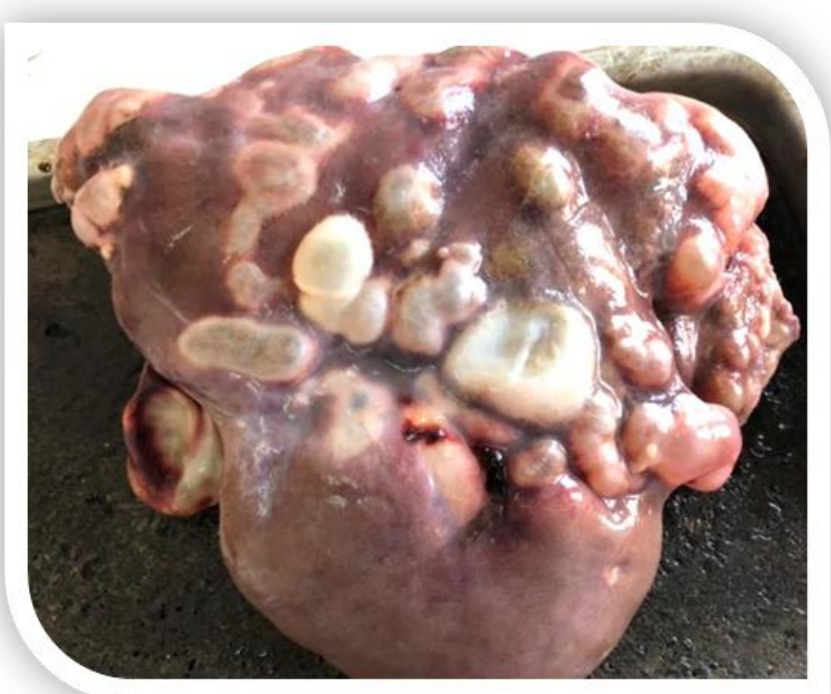

الصورة (1): أكياس عدرية نامية في أكباد أغنام مصابة بالطور اليرقي للمشوكة الحبيبية 


\section{جمع الرؤيسات الأولية Protoscoleces Collection}

استخدمت طريقة (27) Smyth للحصول على الرؤيسات الأولية, وذلك بتعقيم سطح الأكياس العدرية

مرتين بقطن طبي مبلل باليود الكحولي بتركيز 1\%, تم بعد ذلك سحب جزء من سائل الكيس العدري بواسطة

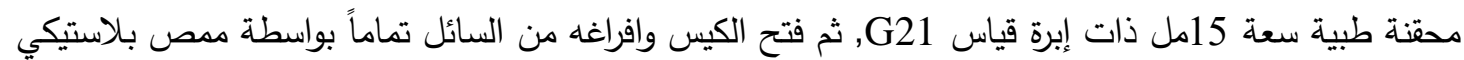

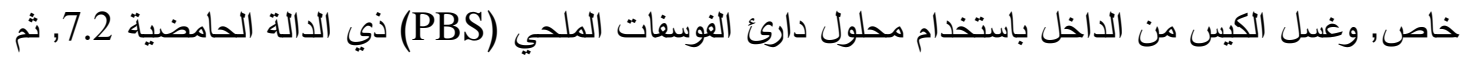

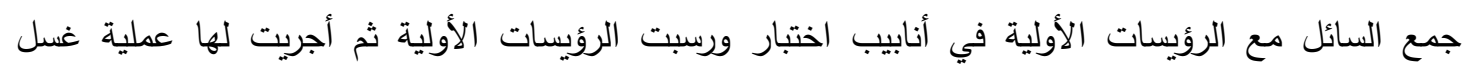
باستخدام المحلول الملحي الدارئ الحاوي على البنسلين Penicillin بتركيز و 1غم ستربتومايسين Streptomycin لكل لتر في محلول الغسل قبل البدء بالغسلة الثانية بجهاز المنبذة نوع Centrifuge الثالثة وأضيف محلول (PBS) المعق للراسب الحاوي على الرؤيسات الأولية.

Estimation of Protoscleces Viability تقدير حيوية الرؤيسات الأولية تم تقدير حيوية الرؤيسات الأولية حسب طريقة (28) Smyth \& Barett وذلك بإضافة 20 مايكرولتر

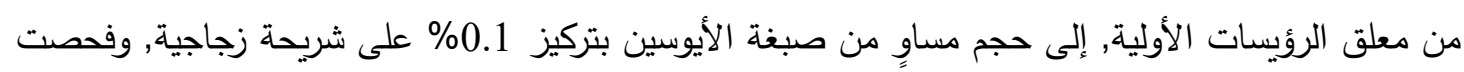
تحت المجهر , ثم عدت الرؤيسات الأولية ذات اللون الأخضر البرّاق (حيّة) لعدم نفاذية أغشيتها لصبغة الصنة الأيوسين Eosin exclusion الأولي بنظر الاعتبار التي تعد من العلامات المهمة أيضاً لفحص الحيوية. وتم حساب الندابة النسبة المئوية لحيوية

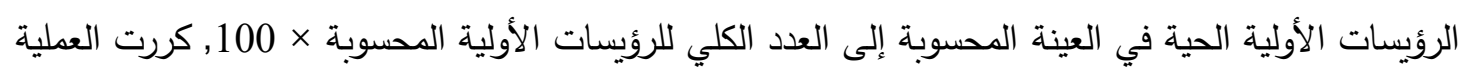

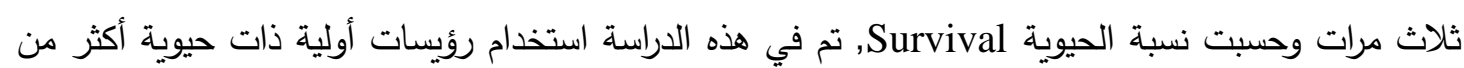

Laboratory Animals الحيوانات المختبرية

استخدمت في هذه الدراسة الفئران السويسرية نوع Mus Musculus سلالة BALB/c التي تم تربيتها

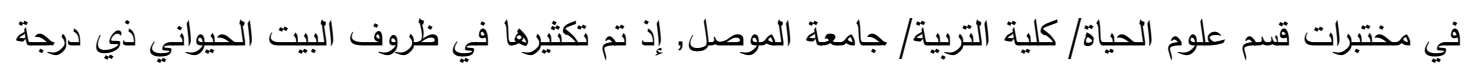

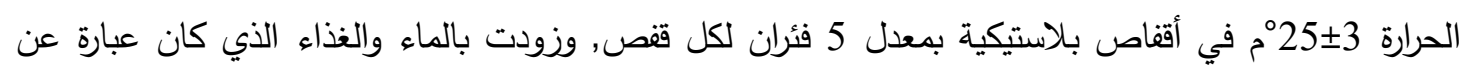

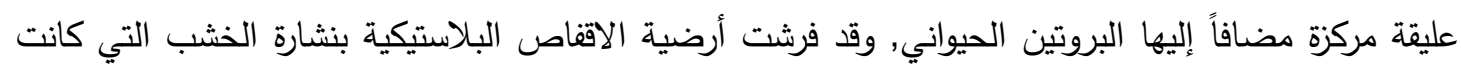

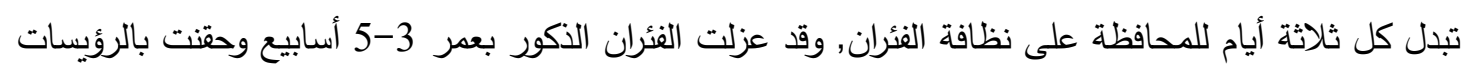
الأولية في التجويف البطني بواسطة إبرة معقدة G21.

البكتربا المستخدمة في الدراسة استخدمت بكتريا L. rhamnosus GG التي تم الحصول عليها من الولايات المتحدة الأمريكية, ولاية كاليفورنيا, بشكل كبسولات, تحتوي كل كبسولة على 10 بليون خلية بكتيرية (الصورة 2), تم تتشيط البكتريا

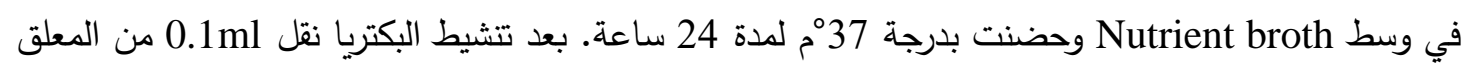

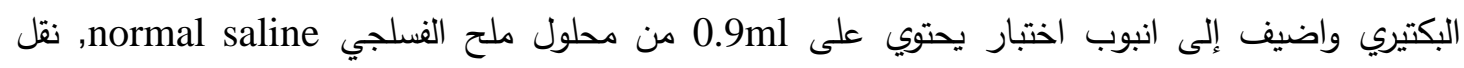

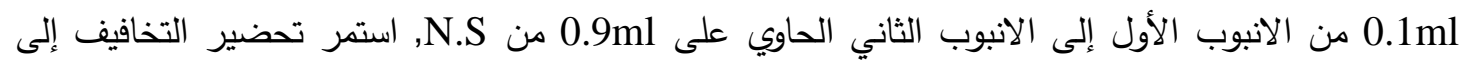


التخفيف السابع. ثم عدت المستعمرات بطريقة التخفيف بأطباق بتري حيث نقل 0.1ml من كل من التخفيفين

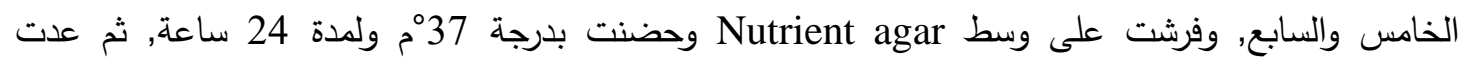

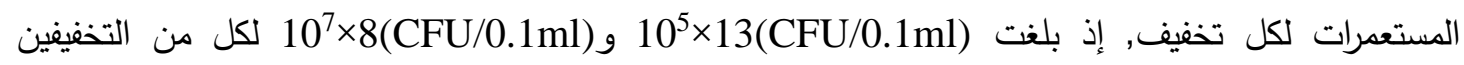
الخامس والسابع, على التوالي. (19, 29).

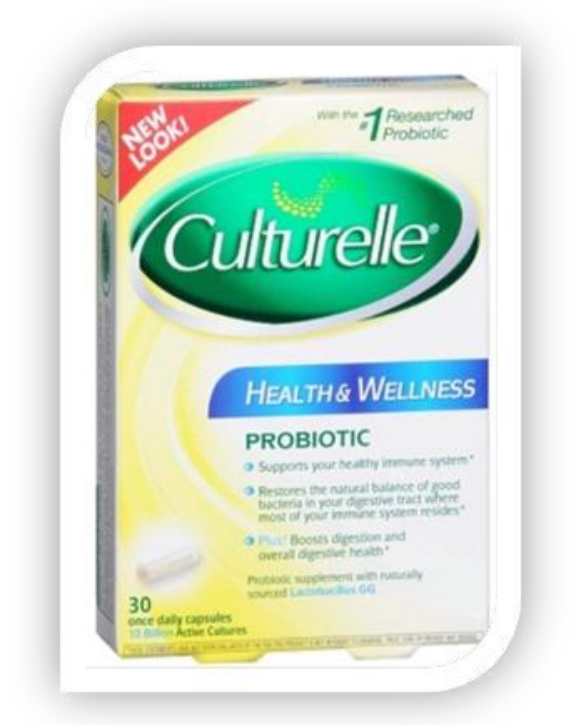

Lactobacillus rhamnosus الصورة (2): بكتريا

Experimental Design Intraperitoneal Injection تصميم التجارب Intraperitoneal Injection الحقن داخل البريتون الجباب المجموعة الأولى تمثل مجموعة السيطرة, التي حقنت بمجموعة ثابتة تضمنت 20 فأراً ذكراً بـ 2000 رؤيس أولي داخل البريتون Intraperitoneally وتضمنت أربع مجاميع بواقع 5 فئران لكل مجموعة, عدت مجاميع السيطرة, وشرحت الفئران بعد شهرين وثلاثة أشهر وأربعة أشهر وخمسة أشهر ماته

المجاميع التجريبية

استخدم 20 فأراً ذكراً قسمت إلى أربع مجاميع بواقع 5 فئران لكل مجموعة, حقنت المجاميع كلها بـ 2000 رؤيس أولي داخل البريتون ثم حقنت هذه المجاميع بعد 24 ساعة بمعلق بكتيري $0.1 \mathrm{ml}$ من L. rhamnosus GG كل 72 ساعة. شرحت فئران المجموعة الأولى بعد شهرين من الإصابة, وشرحت فئران المجموعة الثانية بعد 3 أشهر

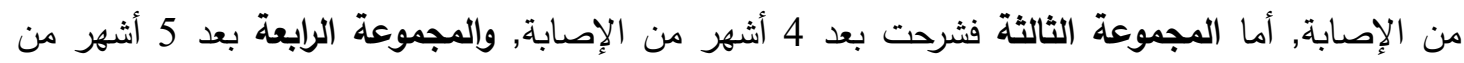
الإصابة, بحيث أن التشريح لجميع المجاميع كان بعد انتهاء حقن البكتريا بـ 72 ساعة.

Orally Inoculation التجريع الفموي

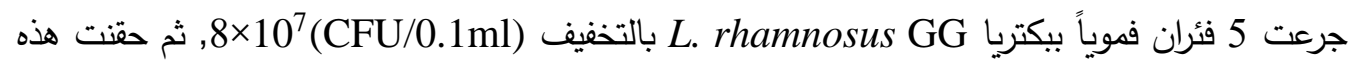

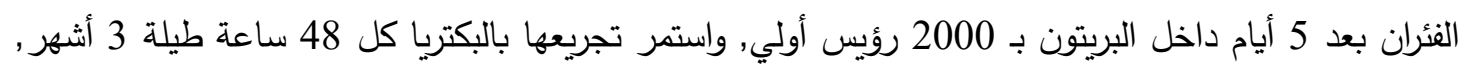
شرحت الفئران بعد يومين من التجريع الأخير بالبكتريا. 
Mice Dissection تشريح الفئران

ثبتت الحيوانات في طبق التشريح الخاص بعد تخديرها بالإيثر , وفتحت البطن للتحري عن وجود

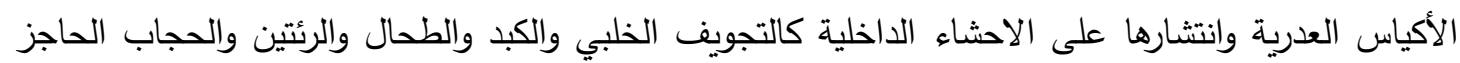
بمساعدة العدسة المكبرة, وتم قياس قطر الأكياس بواسطة القدمة Vernier, وقيس وزن الأكياس النامية بواسطة ميزان حساس.

التحليل الاحصائي

تمت الاستعانة بالبرنامجين الاحصائيين الجاهزين في تتفيذ الإجراءات الاحصائية برنامج (SAS)

(30) Minitab وبرنامج Statistical Analysis System

\section{النتائج}

تأثير البكتريا L. rhamnosus GG في أعداد واوزان وأقطار الأكياس العدرية في الفئران المصابة بالرؤيسات الأولية.

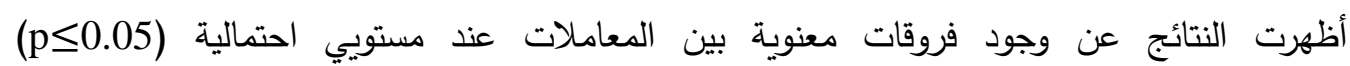
و(p<0.01) الجدول (1-A), وعند اجراء اختبار دنكن أظهرت النتائج انخفاضاً كبيراً وملحوظاً في أعداد وأوزان وأقطار الأكياس العدرية والنسبة المئوية لاختزال أعداد الاكياس العدرية في الفئران المعاملة بيكتريا لمدة شهرين وثلاثة أشهر وأربعة أشهر وخمسة أشهر الجدول (1- rhamnosus GG نسبة اختزال أعداد الأكياس العدرية 98\% بعد خمسة أشهر من الحقن, إذ انخفض معدل عدد الأكياس إلى 1.0

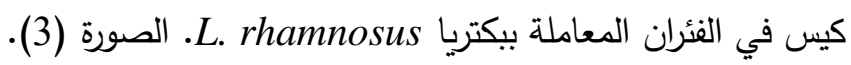

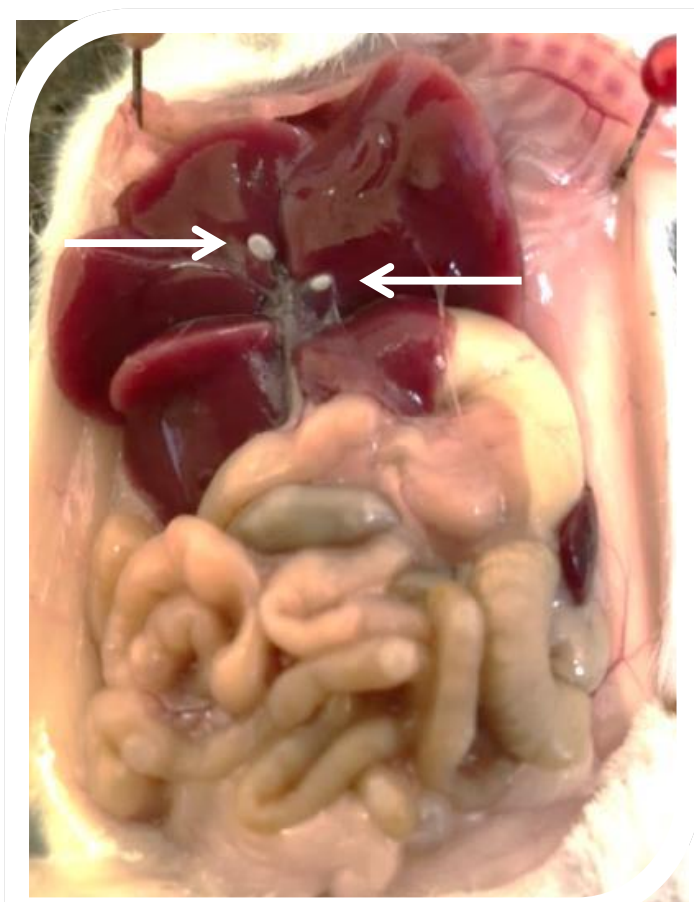

الصورة (3): اكياس عدرية ثانوية نامية في فأر محقون برؤيسات أولية معامل بالبكتريا

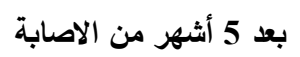




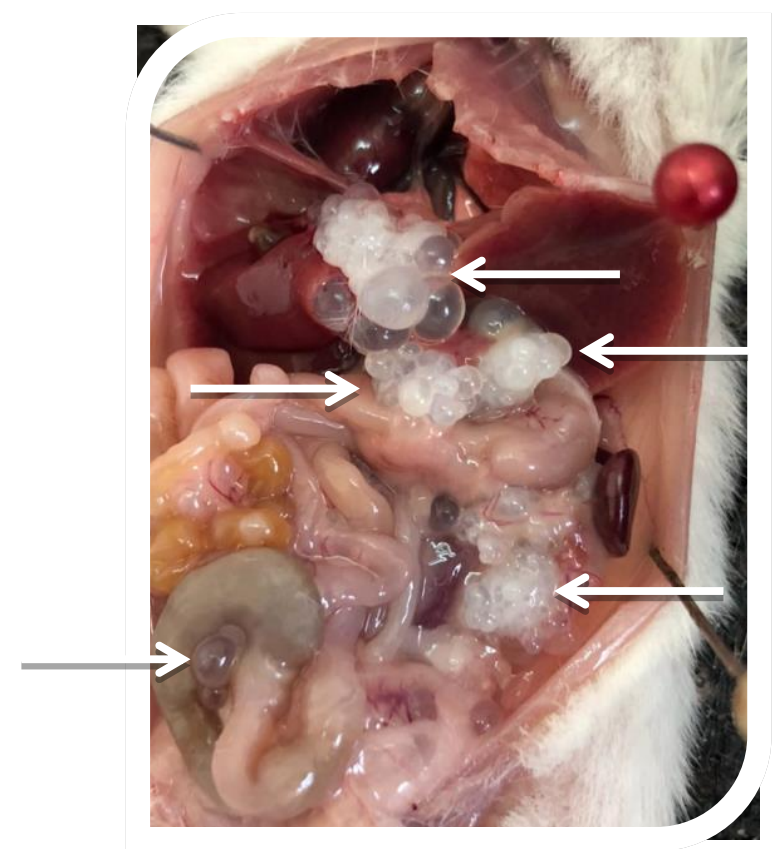

الصورة (4): اكياس عدرية ثانوية نامية في فأر محقون برؤيسات أولية غير معامل (سيطرة) بالبكتريا بعد 5 أشهر من الاصابة

مقارنة بمجموعة السيطرة التي كان معدل عدد الأكياس 42.2 كيس (الصورة 4), وانخفض معدل وزن الأكياس العدرية إلى 0.001 غم في الفئران المعاملة ببكتريا Le. rhamnosus GG, مقارنة بمجموعة السيطرة

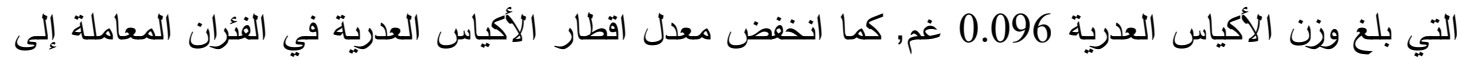
0.08 ملم مقارنة بمجموعة السيطرة إذ بلغ معدل أقطار الأكياس العدرية 0.44 ملم وكانت الفروقات معنوية.

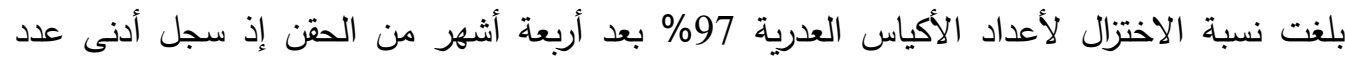

للأكياس العدرية 1.2 كيس في الفئران المعاملة ببكتريا Lrhamnosus GG, الصورة لاديانه (5).

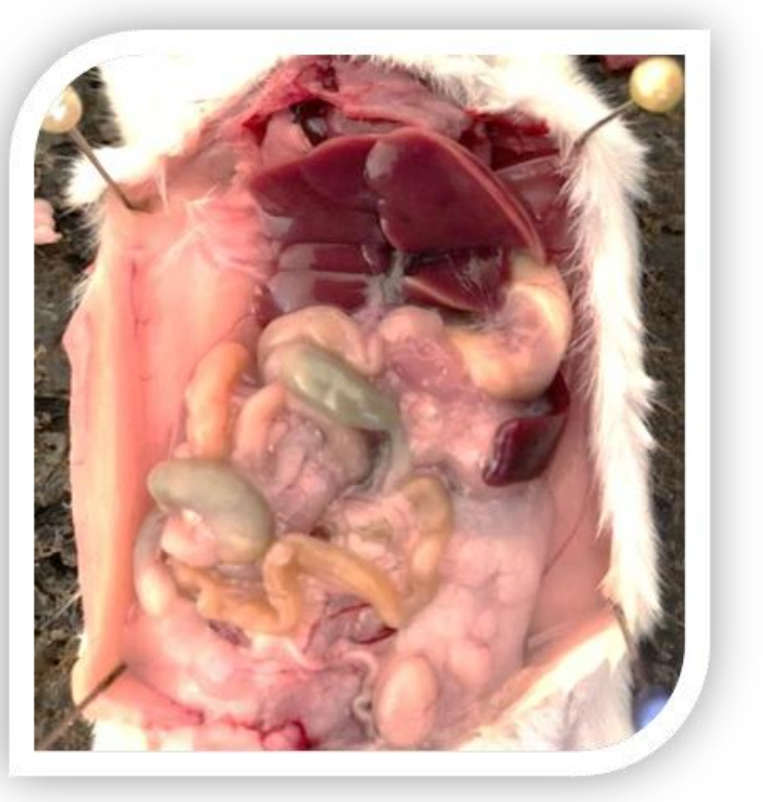

الصورة (5): فأر محقون برؤيسات أولية معامل بالبكتريا بعد 4 أثهر من الإصابة (خالٍ من الأكياس العدرية) 


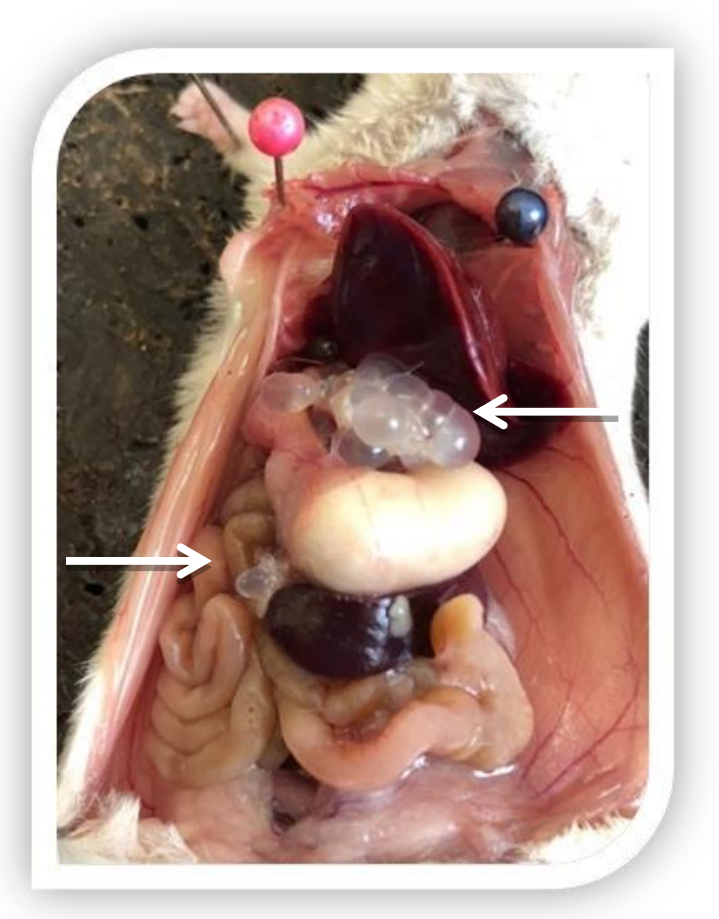

الصورة (6): أكياس عدرية ثانوية نامية في فأر محقون برؤيسات أولية غير معامل (سيطرة) بالبكتريا بعد 4 أشهر من الاصابة

مقارنة بمجموعة السيطرة التي سجلت ارتفاعاً لأعداد الأكياس العدرية بلغ 45.4 كيس (الصورة 6),

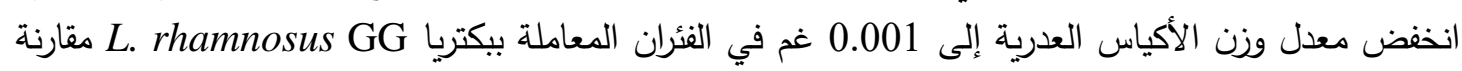

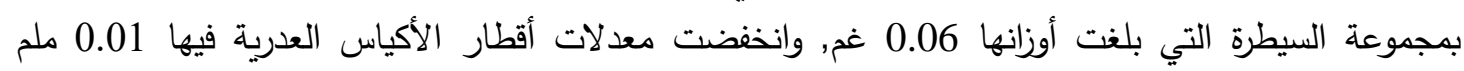
مقارنة بمجموعة السيطرة التي بلغت 0.31 ملم, حيث كانت الفروقات معنوية. بلغت نسبة الاختزال لأعداد

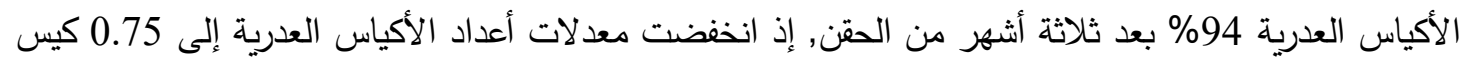

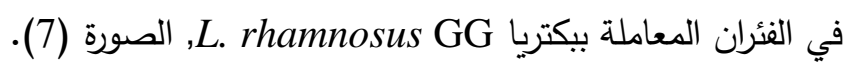

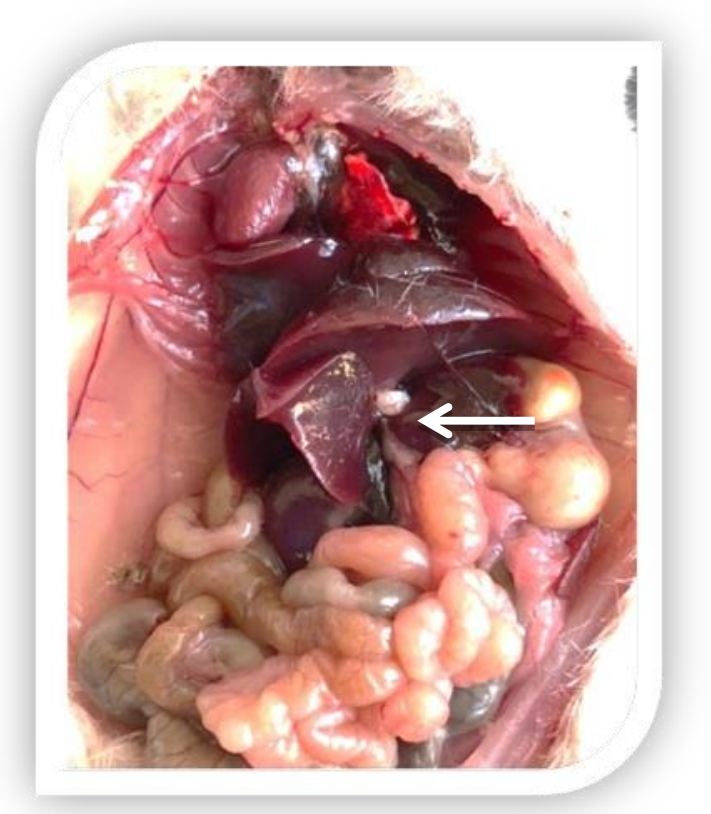

الصورة (7): اكياس عدرية ثانوية نامية في فأر محقون برؤيسات أولية معاملة بالبكتريا بعد 3 أشهر من الإصابة 
مقارنة بمجموعة السيطرة التي بلغت معدلات أعداد الاكياس العدرية 21.2 كيس, الصورة (8).

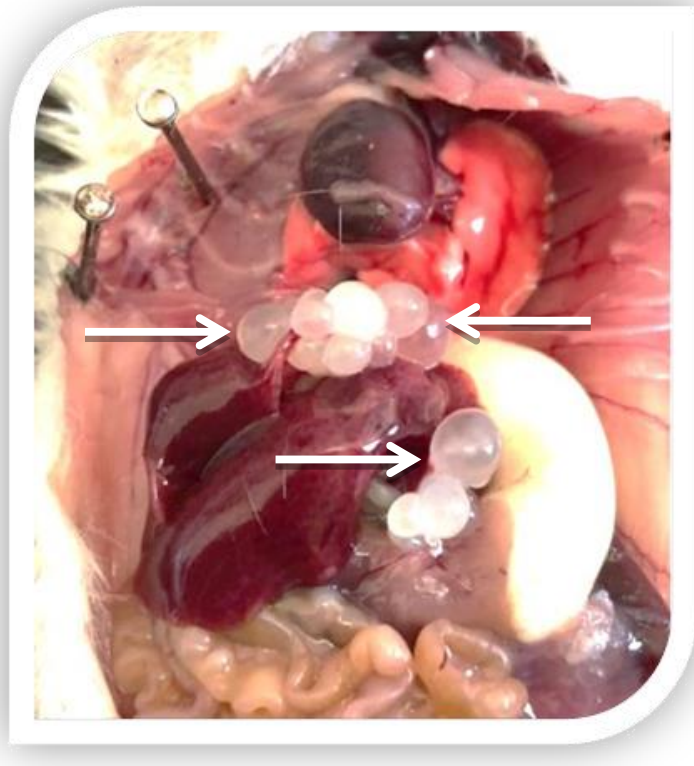

الصورة (8): (كياس عدرية ثانوية نامية في فأر محقون برؤيسات أولية غير معامل (سيطرة) بالبكتريا بعد 3 أشهر من الإصابة

L. rhamnosus GG وانخفض معدل وزن الاكياس العدرية إلى 0.012 غم في الفئران المعاملة بيكتريا مقارنة بمجوعة السيطرة التي بلغت 0.033 غم إذ كانت الفروقات معنوية, كما انخف معدل قطر الأكياس

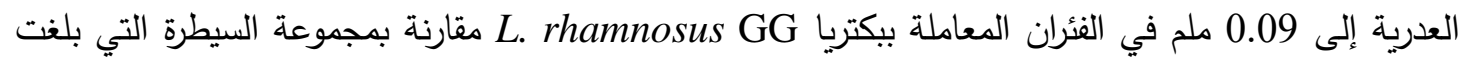
0.42 ملم بعد ثلاثة أشهر من الحقن وكانت الفروقات معنوية. بلغت نسبة الاختزال لأعداد الأكياس العدرية

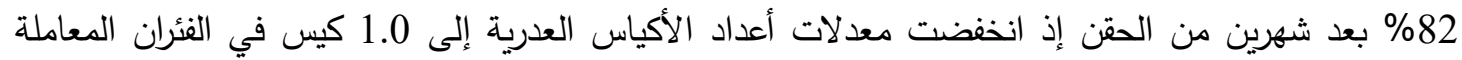
بيكتريا Lhamnosus GG. rhas الصورة (9), مقارنة بمجموعة السيطرة التي بلغت 6.2 كيس الصورة (10).

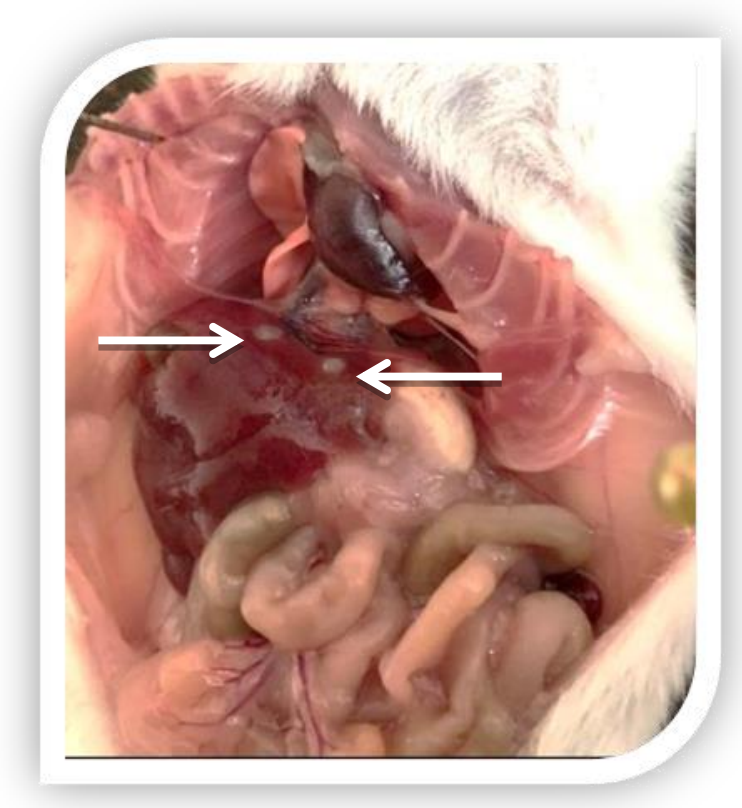

الصورة (9): اكياس عدرية ثانوية نامية في فأر محقون برؤيسات أولية معامل بالبكتريا بعد شهرين من الإصابة 


(2)

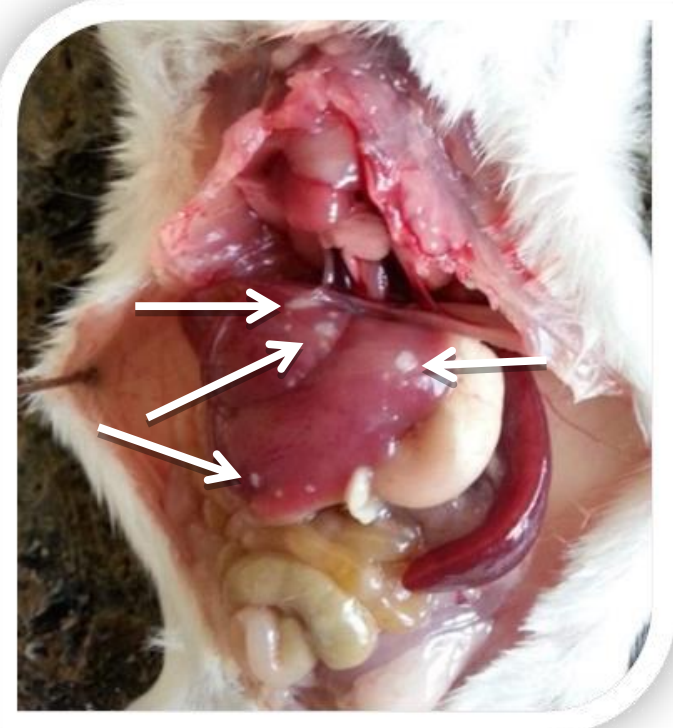

الصورة (10) اكياس عدرية ثانوية نامية في فأر محقون برؤيسات أولية غير معامل (سيطرة) بالبكتريا بعد شهرين من الإصابة

كما انخفض معدل وزن الأكياس العدرية إلى 0.0012 غم في الفئران المعاملة ببكتريا

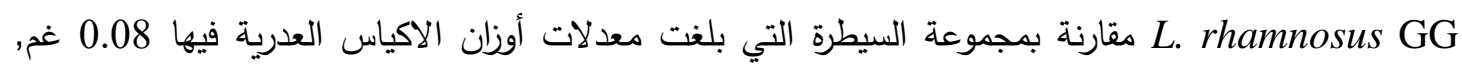

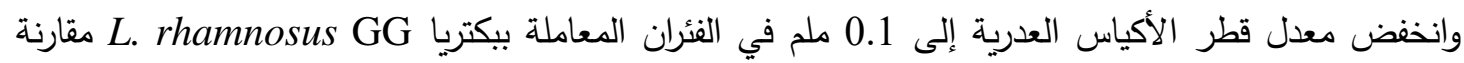
بمجموعة السيطرة التي بلغت أقطار الأكياس العدرية فيها 0.4 ملم وكانت الفروقات معنوية. 


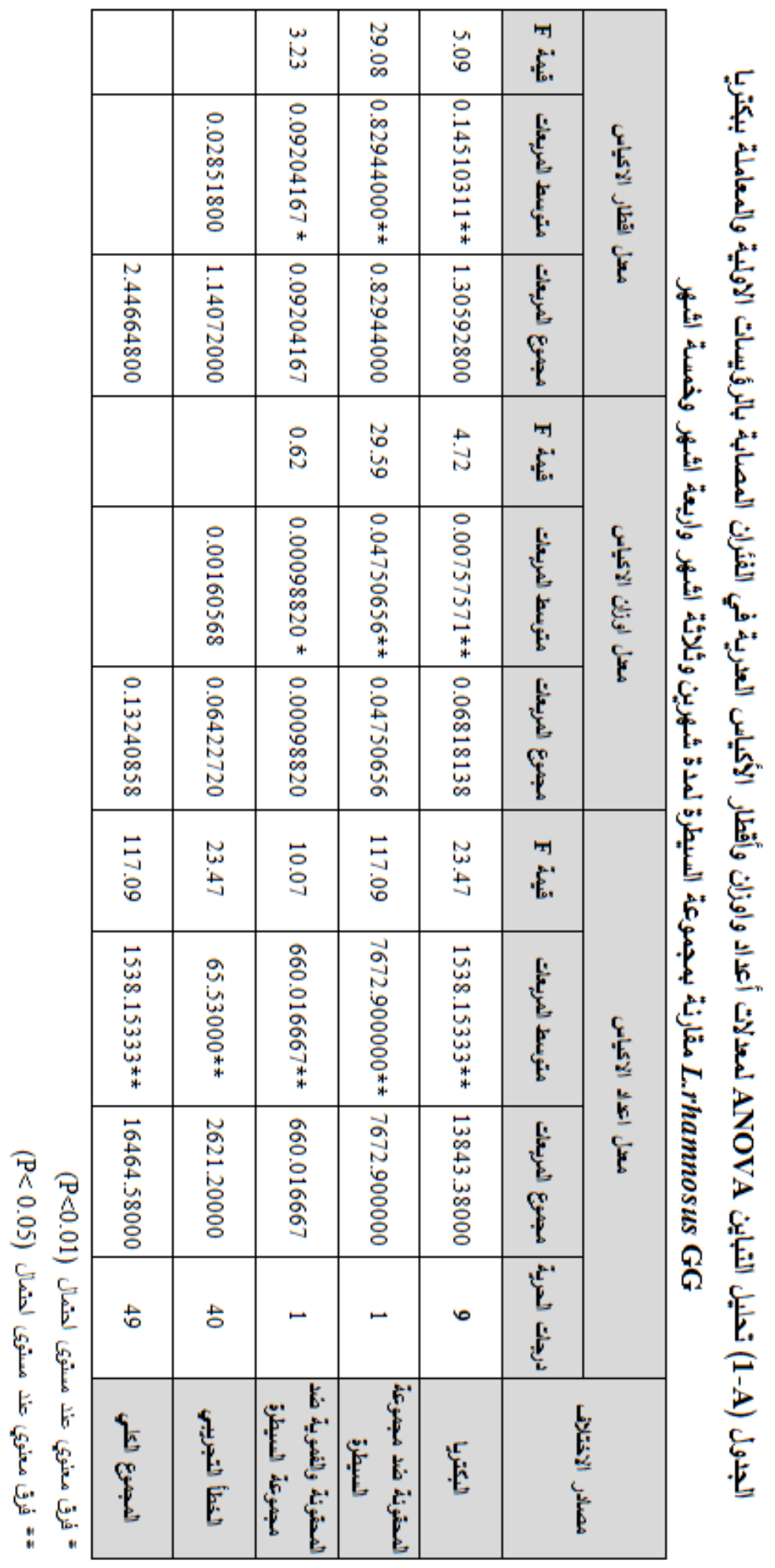


الجدول (B-1): معدلات أعداد وأوزان وأقطار الاكياس العدرية والنسبة المئوية لاختزال اعدادها في الفئران المصابة بالرؤيسات

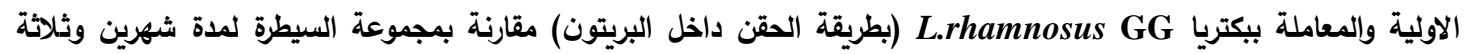

\begin{tabular}{|c|c|c|c|c|c|c|}
\hline \multirow{3}{*}{ للاختزال } & & & & \multicolumn{3}{|c|}{ شهر واربعة أشهر وخمسة أشهر } \\
\hline & \multicolumn{3}{|c|}{ الاكياس العدرية } & \multirow{2}{*}{ عدد المكررات } & \multirow{2}{*}{ الأشهر } & \multirow[b]{2}{*}{ المعاملات } \\
\hline & معدل القطر & معدل الوزن (غم) & معدل العدد & & & \\
\hline \multirow{2}{*}{$82 \%$} & A 0.4780 & A 0.08980 & С 6.200 & 5 & 2 & $\mathrm{C}$ \\
\hline & DC 0.0120 & C 0.00120 & C 1.000 & 5 & 2 & $\mathrm{~T}$ \\
\hline \multirow{2}{*}{$94 \%$} & BA 0.4280 & BC 0.03340 & B 21.200 & 5 & 3 & $\mathrm{C}$ \\
\hline & DC 0.0940 & A 0.12200 & $\mathrm{C} 0.750$ & 5 & 3 & $\mathrm{~T}$ \\
\hline \multirow{2}{*}{$97 \%$} & BAC 0.3100 & BA 0.06800 & A 45.400 & 5 & 4 & $\mathrm{C}$ \\
\hline & D 0.0120 & C 0.00180 & C 1.200 & 5 & 4 & $\mathrm{~T}$ \\
\hline \multirow{2}{*}{$98 \%$} & BA 0.4420 & A 0.09660 & A 42.200 & 5 & 5 & $\mathrm{C}$ \\
\hline & DC 0.0800 & C 0.00100 & C 1.000 & 5 & 5 & $\mathrm{~T}$ \\
\hline
\end{tabular}

C: مجموعة السيطرة Control. T: المجموعة المعاملة Treated. الحروف المتثابهة تعني عدم وجود فروق معنوية. الحروف المختلفة تعني وجود فروق معنوية.

كما أظهرت النتائج أن معدل أعداد وأوزان وأقطار الأكياس العدرية والنسبة المئوية لاختزالها في تجربة التجريع الفوي ببكتريا L. rhamnosus GG التي جرعت قبل الإصابة بالرؤيسات الأولية بـ (3) أيام preinfection الفئران المجرعة بالبكتريا, كما انخفض معدل أعداد الاكياس العدرية إلى 1.0 كيس, الجدول (2) والصورة (11).

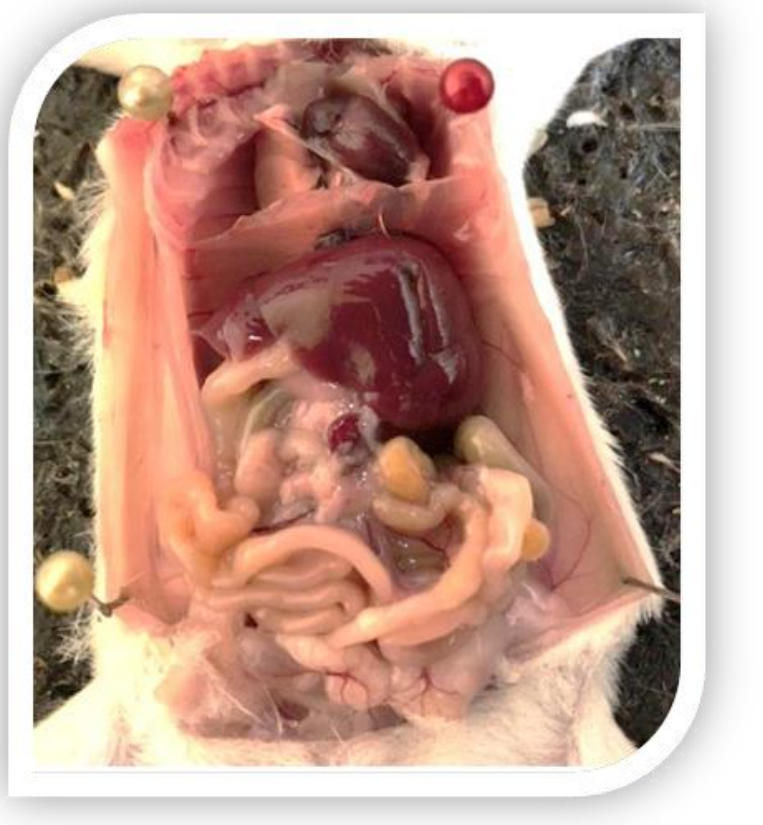

الصورة (11): فأر مجرع بالبكتريا محقون بالرؤيسات الأولية لددة 3 أثهر (خالٍ من الأكياس العدرية) 


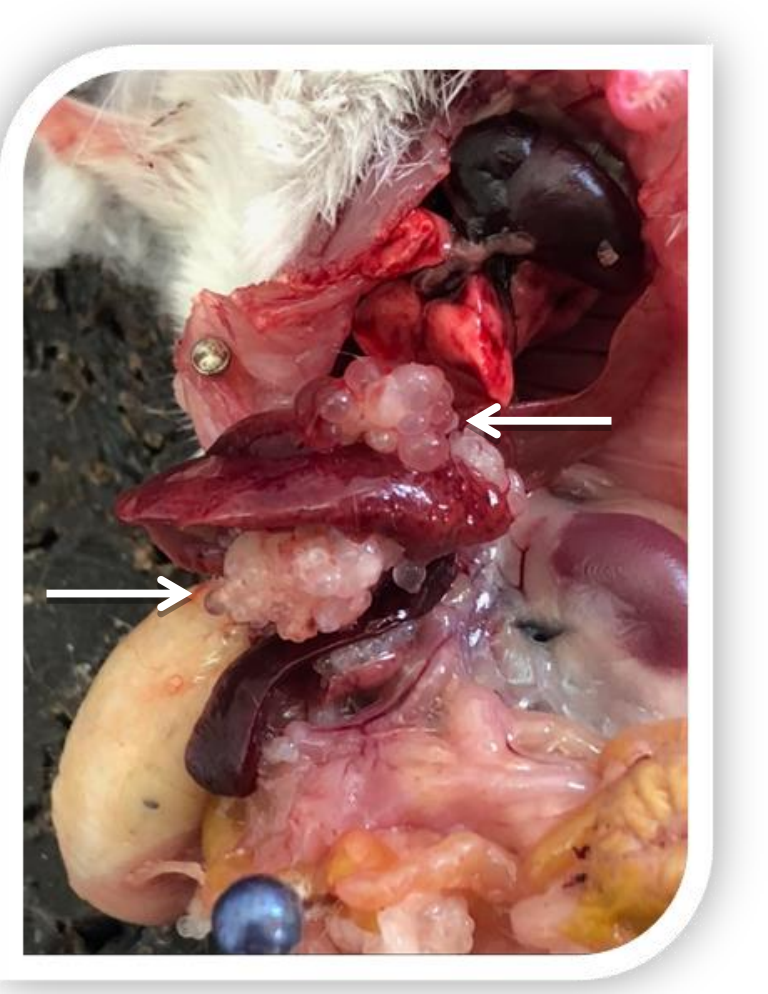

الصورة (12): فأر محقون بالرؤيسات الأولية (السيطرة) لددة 3 أثهر من الإصابة

مقارنة بمجموعة السيطرة التي بلغ معدل أعداد الاكياس العدرية فيها 21.2 كيس (الصورة 12),

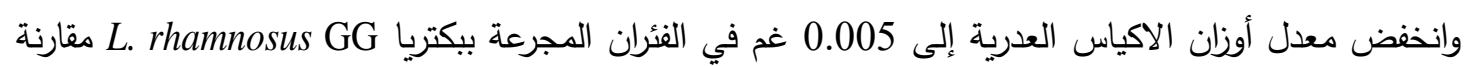

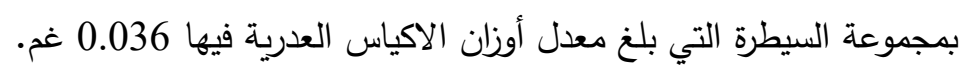

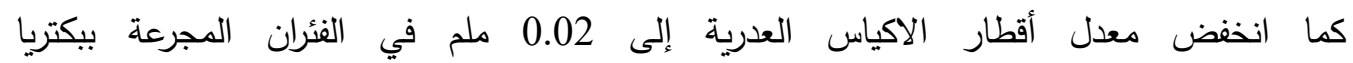
Le. rhamnosus GG الفروقات معنوية.

الجدول (2): معدل أعداد وأوزان وأقطار الأكياس العدرية والنسبة المئوية لاختزال أعدادها في الفئران المجرعة بيكتريا

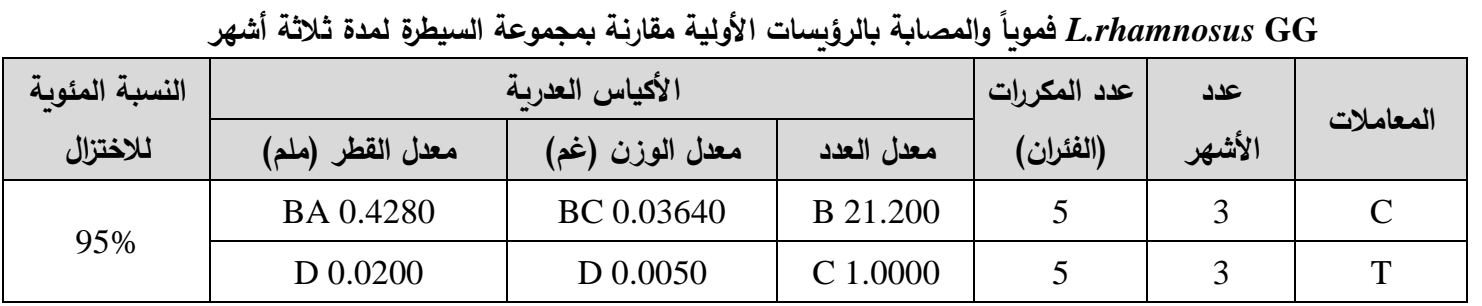

Treated مجموعة السيطرة T.Control : المجموعة المعاملة : C الحروف المتثابهة تعني عدم وجود فروق معنوية. الحروف المختلفة تعني وجود فروق معنوية.

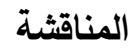

تعتمد كفاءة البكتريا المفيدة للمضيف على الميكانيكية التي بواسطتها أن تحدث تأثيراً. قد تضم هذه

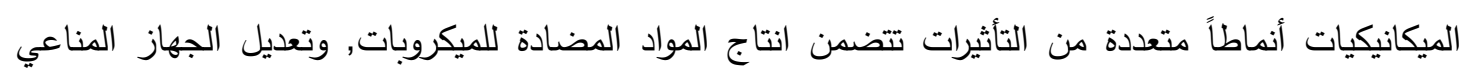


المخاطي, وتغيير الكائنات الدقيقة Microflora المناعية وتعزيز الفعالية الانزيمية (31), ان النمط الأولي

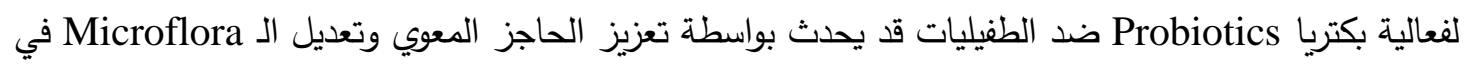
المعي (32,33,34), قد تزيد بكتريا Probiotics عدد الكائنات المجهرية مثل بكتريا Lactobacilli التي بكزيا بدورها تتبط نمو الكائنات الممرضة بواسطة التتافس على مواقع الالتصاق في المخاطية المعوية. كما تتضمن

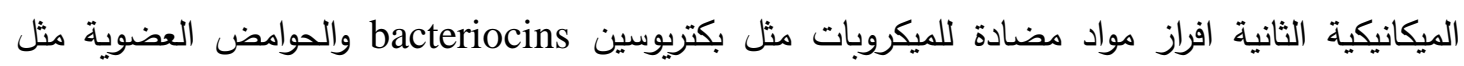
حامض اللاكتيك Lactic acid وحامض الاستيتيك Acetic acid وحامض البيوتيريك Butyric acid التي تفرز بصورة رئيسة من قبل أنواع الـ Lactobacillus التي تمتلك تأثيراً قاتلاً على يرقات الطفيليات (35).

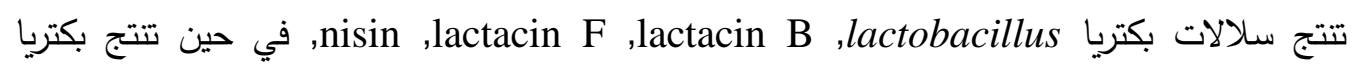

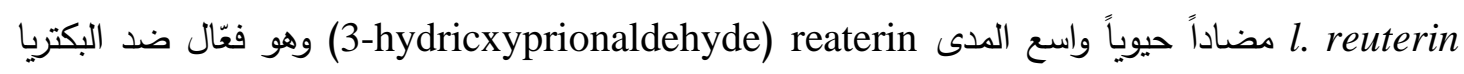
والخمائر والفطريات والأوالي والفيروسات (36) بواسطة تقليل الدالة الحامضية المعوية الموضعية عن طريق انتاج Probiotics يمكن أن تحور نمو الكائنات الدقيقة الحساسة للحامضية. ولبكتريا ميزة تعديل المناعة بواسطة تحفيز الاستجابة المناعية للمضيف تجاه مختلف الكائنات الممرضة.

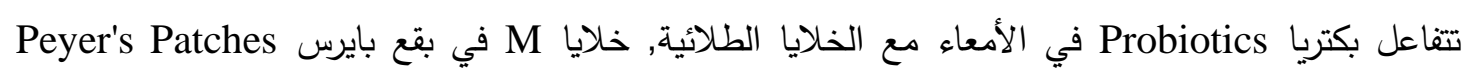

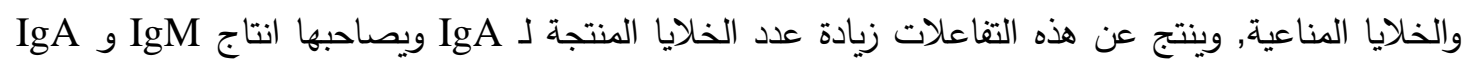

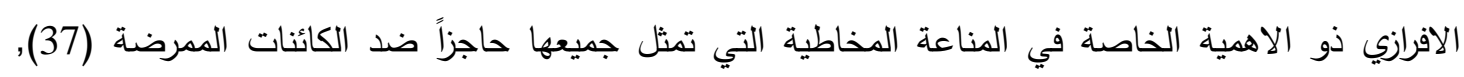

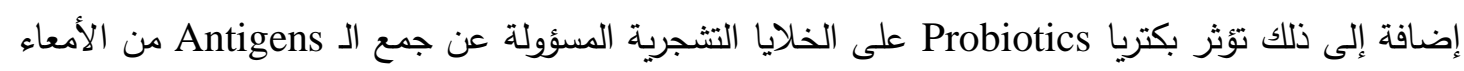
وتقديمها إلى خلايا T الطبيعية المؤدية إلى تمايزها لخلايا Th1, Th2) المساعدة أو الخلايا اللمفاوية

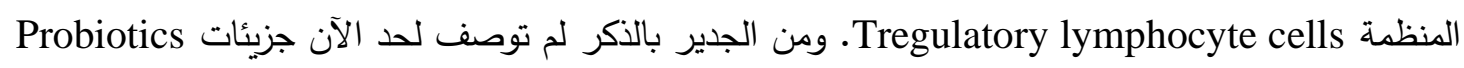

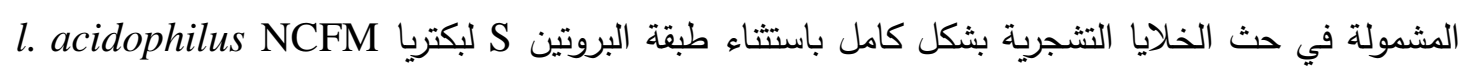

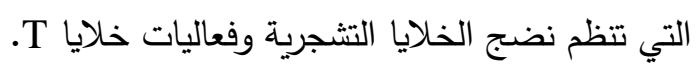
حديثاً هناك دراسات عديدة تحرت عن امكانية الـ Probiotics في السيطرة على تكاثر الممرضات حقيقية النواة اما في المعي مثل الـ Probiotics أو في أجزاء أخرى, ودعم هذا المفهوم بالدراسات الحديثة التي

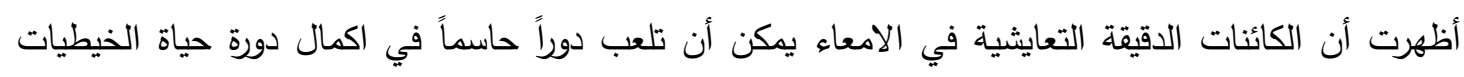

الطفيلية المعوية Trichurs muris وتعديل الاستجابة المناعية للمضيف (38). توافقت نتائج الدراسة الحالية مع دراستي (39) ت Dea-Ayuela, Rama-Iñiguez, \& BolásMcClemens et al., (40), Fernandez اصابات الديدان الخيطية المعوية بالدودة السوطية T.muris إذ تبين أن اعطاء المكملات الغذائية فموياً ببكتريا 1×109 CFU علد الكل يوم سرع بثكل معنوي ازالة اليرقات في الفئران

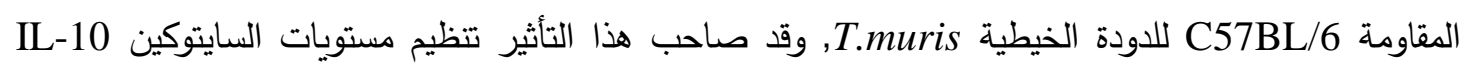

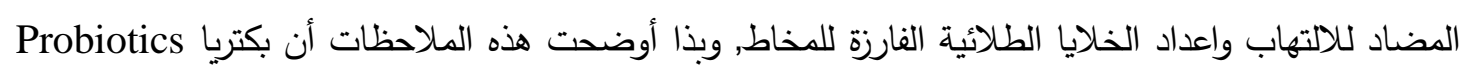

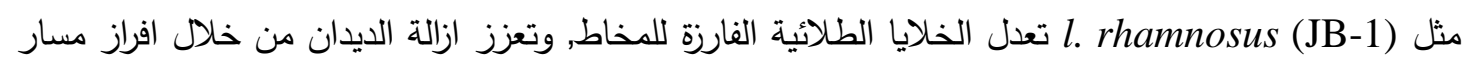
(IL-10) lactobacillus ن.muris

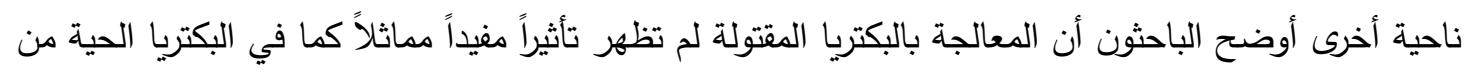


حيث طرح الديدان والتغيرات المناعية, هذه المعلومات تقترح ان التأثيرات الايجابية لا تعزى فقط إلى تركيب البكتريا ولكن أيضاً الى الناتج المفرز المنتشر من البكتريا أو إلى التفاعلات بين المضيف التيف والبكتريا الحية, كما

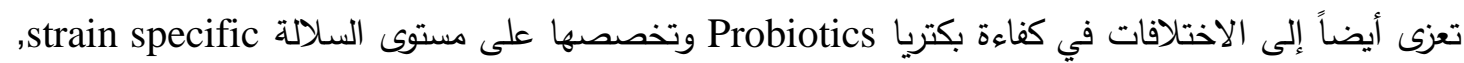
وتتوع تصميم الدراسة, فضلاً عن الحيوانات المختبرية المستخدمة ومديات الجرعة المعطاة وطريقة التجريع. توافقت هذه الدراسة أيضاً مع دراسات باحثين آخرين الذين استخدموا بكتريا Probiotics المحفزة للمناعة ضد الإصابة بالدودة الخيطية Trichinella spiralis التي عدت نموذجاً لتقييم الصفات المعدلة والمناعية والمضادة للديدان لبكتريا Probiotics, وكذلك لسلالات البكتريا المنتجة للبكتريوسين $(43,44)$,

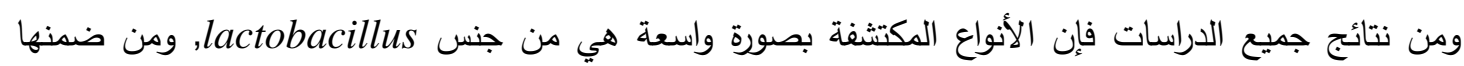
كانت l. casie أكثرها تأثيراً مضاداً للديدان بكفاءة تراوحت بين 75-100\% وقاع وائة من الديدان. كما أظهرت سلالة بكتريا Tlantaruml P164 درجة وقاية 90\% من الدودة الخيطية T.spiralis, وهكذا اقترح الباحثون أن سلالات بكتريا lactobacillus المذكورة آنفاً تكون آمنة باستخدامها بكتريا Probiotics علاجية ووقائية

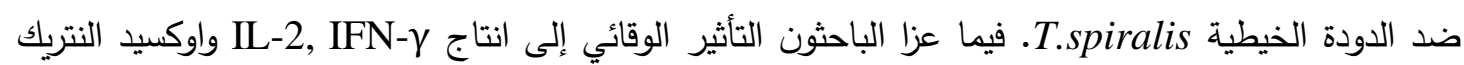

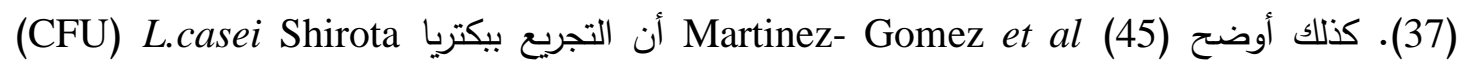
1 ×8 داخل البريتون, لمرة واحدة في الاسبوع ولمدة 3 أسابيع لـ 60 فأراً اعطوا جرعة تحتوي على بكسا 200 يرقة من T.spiralis أدى إلى نقص معنوي في أعداد الطفيليات الناضجة في معي الفئران. توافقت نتائج الدراسة الحالية أيضاً مع دراسة (46) . Basualdo et al الذي استخدم (CFU/ml)

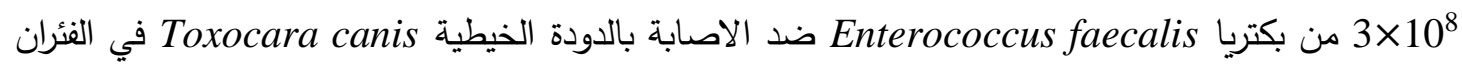

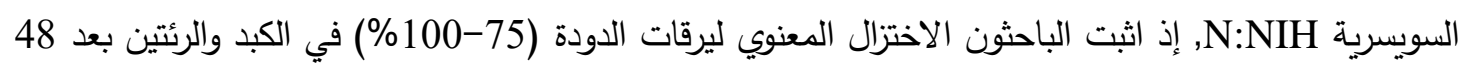

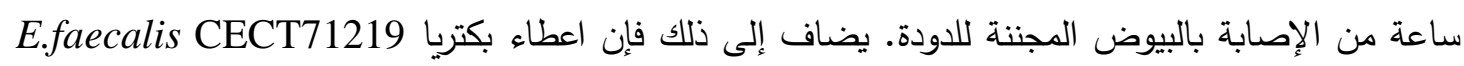

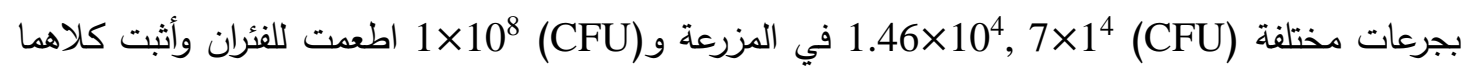
تأثيراً مضاداً قاتلاً لليرقات خارج وداخل الجسم (47). أظهرت الدراسة الحالية توافقاً مع دراسة (18) Coêlho et al. الذين وضعوا ستراتيجيات وقائية جديدة ضد الاصابة بالديدان الثصية Hook worms وتضمنت استخدام بكتريا Probiotics لهذا الغرض بعد ان لاحظوا حدوث مقاومة للأدوية عند الاصابة بهذه الديدان سواء كانت في الإنسان أو في الكلاب, لإبات إذ وجدوا ان اعطاء معلق CFU)106x1) من كل من السلالات LFل delbrueckii H2B20, 28 L. Llantarum ATCC8014, L. acidophilus

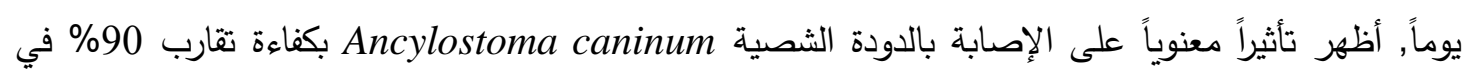

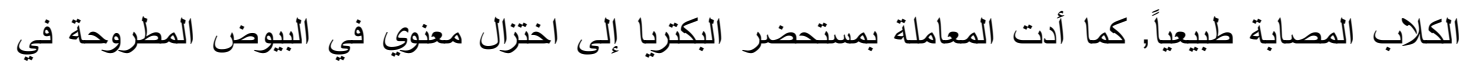

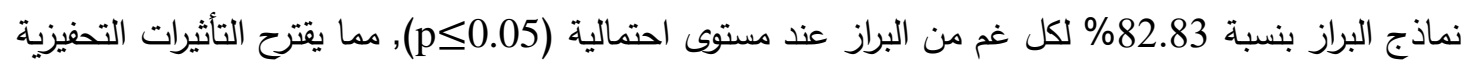

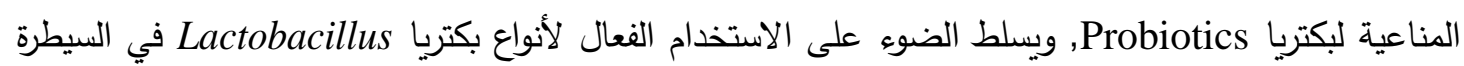
على داء الشصيات في الكلاب. يمكن الاستتتاج بأن الوسائل العلاجية ببكتريا Probiotics يمكن أن يساعد في تقليل أو اختزال مخاطر

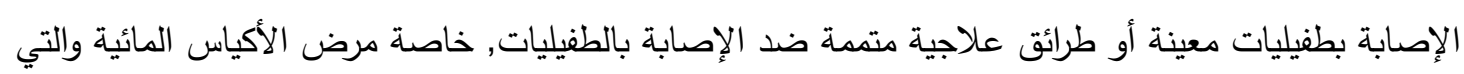

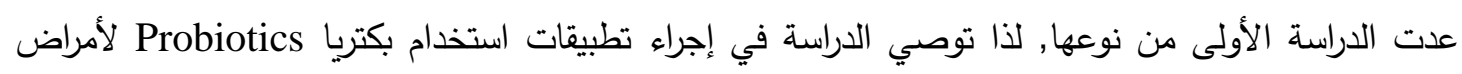

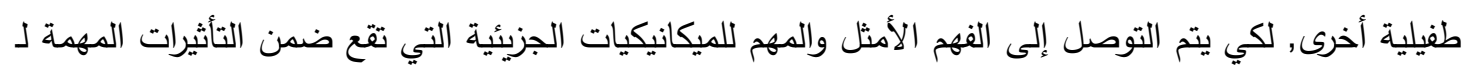


على الإصابات الطفيلية من ناحية واستخدامها كوسيلة قتل الرؤيسات الأولية قبل إجراء العمليات الجراحية لاستئصال الأكياس العدرية من ناحية أخرى.

\section{Conclusion}

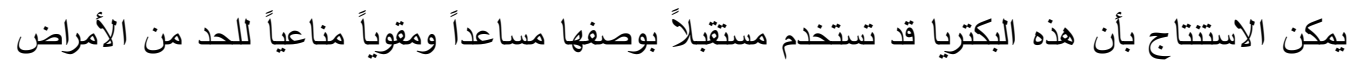

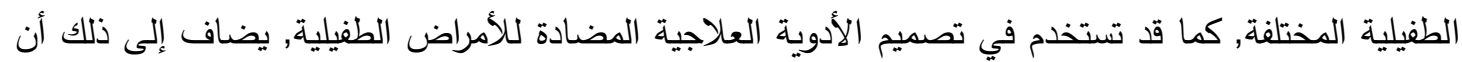

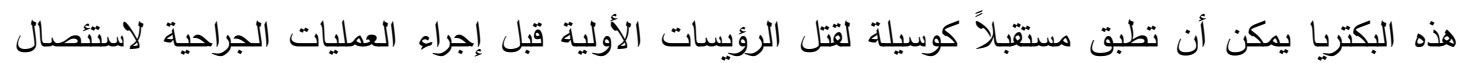

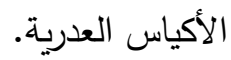

\section{المصادر}

1) Mihmanli, M., Idiz, U. O., Kaya, C., Demir, U., Bostanci, O., Omeroglu, S., \& Bozkurt, E. (2016). World journal of hepatology, 8 (28), 1169-1181.

2) Possenti, A., Manzano-Román, R., Sanchez-Ovejero, C., Boufana, B., La Torre, G., Siles-Lucas, M., \& Casulli, A. (2016). PLoS neglected tropical diseases, 10 (11), e0005114.

3) Van Cauteren, D., Millon, L., De Valk, H., \& Grenouillet, F. (2016). Parasitology Research, 115 (11), 4261-4265.

4) Brunetti, E., Kern, P., \& Vuitton, D. A. (2010). Acta tropica, 114 (1), 1-16.

5) Mezioug, D., \& Touil-Boukoffa, C. (2012). Eur Cytokine Netw, 23 (3), 112-119.

6) Matera, G., Loria, M. T., Peronace, C., Catanzariti, T., Settembre, P., Giancotti, A., Foca, A. (2018).Mediators Inflamm, 2018, 4283672. doi: $10.1155 / 2018 / 4283672$.

7) Chen, X., Zhang, R., \& Wen, H. (2018). BioMed research international, 2018.

8) Cai, H., Chen, L. L., Ye, B., Liu, A. B., Zhang, J., \& Zhao, Y. F. (2013). Parasitol Res, 112 (2), 707-717. doi: 10.1007/s00436-012-3191-4.

9) Nayman, A., Guler, I., Keskin, S., Erdem, T. B., Borazan, H., Kucukapan, A.,... Feyzioglu, B. (2016). Diagnostic and Interventional Radiology, 22 (1): 47-51.

10) Zou, X., Wang, J., Zhao, H., Zhang, J., Wu, W., \& Ye, B. (2009). Experimental Parasitology, 121 (4), 312-316.

11) Lamonaca, V., Virga, A., Minervini, M. I., Di Stefano, R., Provenzani, A., Tagliareni, P. \& Palazzo, U. (2009). World Journal of Gastroenterology: WJG, 15 (26), 3232-3239.

12) Christian, D. J., Khithani, A., \& Jeyarajah, D. R. (2011). The American Surgeon, 77 (4), 417-421.

13) Stoot, J., Jongsma, C., Limantoro, I., Terpstra, O., \& Breslau, P. (2010). World journal of surgery, 34 (1), 106-113.

14) Liu, A.-B., Cai, H., Ye, B., Chen, L.-L., Wang, M.-Y., Zhang, J., \& Zhao, Y.-F. (2013). Parasitology Research, 112 (5), 1865-1875.

15) Imankulov, S., Fedotovskikh, G., Shaimardanova, G., Yerlan, M., \& Zhampeisov, N. (2015). Ultrasonics sonochemistry, 27, 712-716.

16) Yilmaz, M., Akbulut, S., Kahraman, A., \& Yilmaz, S. (2012). International Surgery, 97 (3), 239-244.

17) Bakan, S. (2016).Turkish Journal of Thoracic and Cardiovascular Surgery, 24 (3): 592-595.

18) Coêlho, M. D. G., Coêlho, F. A. d. S., \& Mancilha, I. M. d. (2013). Journal of Parasitology Research, (2013): 1-6.

19) Mohamed, A. H., Osman, G. Y., Zowail, M. E., \& El-Esawy, H. M. (2016). Journal of Parasitic Diseases, 40 (3): 823-832.

20) Reda, A. A. (2018). Journal of Veterinary Medicine, 2018. 
21) Markowiak, P., \& Śliżewska, K. (2017). Nutrients, 9 (9), 1021.

22) Pender, C. M., Kim, S., Potter, T. D., Ritzi, M. M., Young, M., \& Dalloul, R. A. (2017). Poultry Science, 96 (5), 1052-1062.

23) Getachew, T. (2016). J. World Poult. Res, 6, 31-36.

24) Stringfellow, K., Caldwell, D., Lee, J., Mohnl, M., Beltran, R., Schatzmayr, G., Farnell, M. (2011). Poultry Science, 90 (8), 1652-1658.

25) Doron, S., Snydman, D. R., \& Gorbach, S. L. (2005). Gastroenterology Clinics, 34 (3), 483-498.

26) Segers, M. E., \& Lebeer, S. (2014). Towards a better understanding of Lactobacillus rhamnosus GG-host interactions. Paper presented at the Microbial cell factories.

27) Smyth, J. (1985). Proceedings of the 13 th Int. Congr. Hydatidology. Madrid, 8489.

28) Smyth, J., \& Barrett, N. (1980). Transactions of the Royal Society of Tropical Medicine and Hygiene, 74 (5), 649-652.

29) Goyal, N., Tiwari, R. P., \& Shukla, G. (2011). Lactobacillus rhamnosus GG as an effective probiotic for murine giardiasis. Interdisciplinary perspectives on infectious diseases, 2011.

30) Al-Zubaidy, K. M. D. and M. A. Al-Falahy (2016), principle and procedures of statistics and experimental. Duhok University, press, Iraq.

31) Bajagai, Y. S., Klieve, A. V., Dart, P. J., \& Bryden, W. L. (2016). Probiotics in animal nutrition: production, impact and regulation: FAO.

32) Holm, J. B., Sorobetea, D., Kiilerich, P., Ramayo-Caldas, Y., Estellé, J., Ma, T.,.. Svensson \& Frej, M. (2015). PloS one, 10 (5), e0125495.

33) Dvorožňáková, E., Bucková, B., Hurníková, Z., Revajová, V., \& Lauková, A. (2016). Veterinary Parasitology, 231, 69-76.

34) De Avila, L. d. C., de Leon, P., De Moura, M., Berne, M., Scaini, C., \& Leivas Leite, F. (2016). Parasite Immunology, 38 (5), 326-330.

35) De Keersmaecker, S. C., Verhoeven, T. L., Desair, J., Marchal, K., Vanderleyden, J., \& Nagy, I. (2006). FEMS Microbiology Letters, 259 (1), 89-96.

36) Cleusix, V., Lacroix, C., Vollenweider, S., \& Le Blay, G. (2008). FEMS Microbiology Ecology, 63 (1), 56-64.

37) Travers, M.-A., Florent, I., Kohl, L., \& Grellier, P. (2011). Journal of parasitology Research, (2011): 1-11.

38) Hayes, K., Bancroft, A., Goldrick, M., Portsmouth, C., Roberts, I., \& Grencis, R. (2010). Science, 328 (5984), 1391-1394.

39) Dea-Ayuela, M. A., Rama-Iñiguez, S., \& Bolás-Fernandez, F. (2008). International immunopharmacology, 8 (1), 28-35.

40) McClemens, J., Kim, J. J., Wang, H., Mao, Y.-K., Collins, M., Kunze, W. \& Khan, W. I. (2013). Clin. Vaccine Immunol., 20 (6), 818-826.

41) Bär, A.-K., Phukan, N., Pinheiro, J., \& Simoes-Barbosa, A. (2015). PLoS neglected tropical diseases, 9 (12), e0004176.

42) Zaiss, M., \& Harris, N. (2016). Parasite immunology, 38 (1), 5-11.

43) Martínez-Gómez, F., Fuentes-Castro, B. E., \& Bautista-Garfias, C. R. (2011). Parasitology Research, 109 (6), 1609-1617.

44) Temsahy, M. M. E., Ibrahim, I.R., Mossallam, S.F., Mahrous, H., Bary, A.A., \&Salam, A.A.(2015). Veterinary Parasitology,214,3:303-314.

45) Martínez-Gómez, F., Santiago-Rosales, R., \& Bautista-Garfias, C. R. (2009). Veterinary Parasitology, 162 (1-2), 171-175.

46) Basualdo, J., Sparo, M., Chiodo, P., Ciarmela, M., \& Minvielle, M. (2007). Annals of Tropical Medicine \& Parasitology, 101 (6), 559-562.

47) Chiodo, P. G., Sparo, M. D., Pezzani, B. C., Minvielle, M. C., \& Basualdo, J. A. (2010). Memórias do Instituto Oswaldo Cruz, 105 (5), 615-620. 
Use of Lactobacillus rhamnosus GG Agaist Infection with Secondary Hydatid Disease in Swiss BABA/c Mice

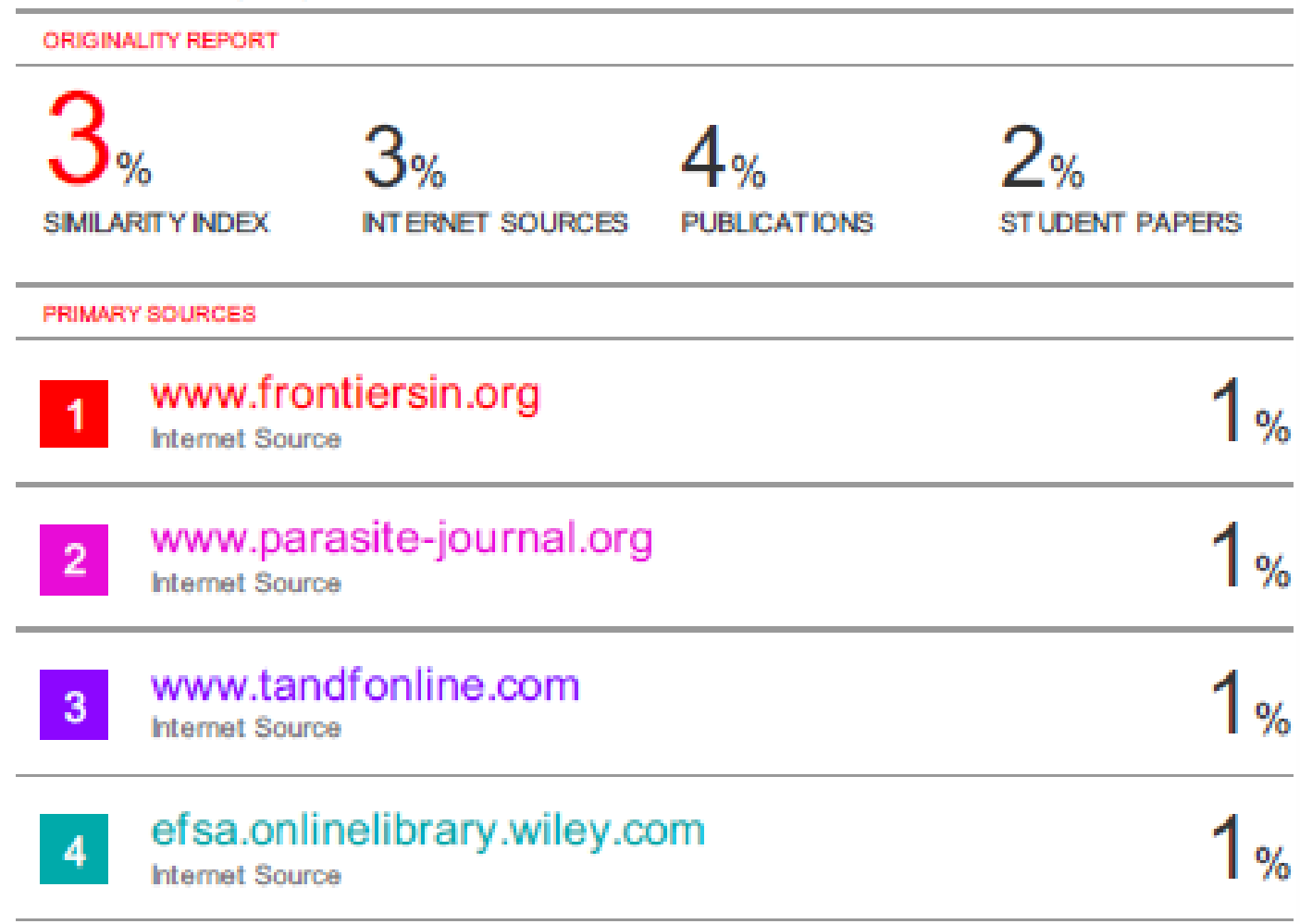

Exclude quotes

Off

Exclude matches

$<1 \%$

Exclude bibliography

On 